Published in final edited form as:

Nat Immunol. 2016 November ; 17(11): 1291-1299. doi:10.1038/ni.3553.

\title{
Evidence of innate lymphoid cell redundancy in humans
}

\author{
Frédéric Vély ${ }^{1,2}$, Vincent Barlogis ${ }^{3,4}$, Blandine Vallentin ${ }^{3}$, Bénédicte Neven ${ }^{4,5,6,7}$, Christelle \\ Piperoglou ${ }^{1,2}$, Thibaut Perchet ${ }^{8,9}$, Maxime Petit ${ }^{8,9}$, Nadia Yessaad ${ }^{10}$, Fabien Touzot ${ }^{5,11}$, \\ Julie Bruneau ${ }^{5,12}$, Nizar Mahlaoui ${ }^{4,5,6,7}$, Nicolas Zucchini ${ }^{13}$, Catherine Farnarier ${ }^{2}$, Gérard \\ Michel $^{3}$, Despina Moshous ${ }^{4,5,6,7}$, Stéphane Blanche ${ }^{4,5,6,7}$, Arnaud Dujardin ${ }^{14}$, Hergen \\ Spits $^{15}$, Jörg H. W. Distler ${ }^{16}$, Andreas Ramming ${ }^{16}$, Capucine Picard ${ }^{4,5,6,7,17}$, Rachel

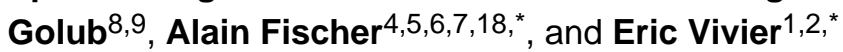

\begin{abstract}
${ }^{1}$ Aix Marseille Univ, CNRS, INSERM, CIML, Marseille, France ${ }^{2}$ APHM, Hôpital de la Conception, Service d'Immunologie, Marseille, France ${ }^{3} \mathrm{APHM}$, Hôpital de la Timone, Service d'Hématologie et Oncologie Pédiatrique, Marseille, France ${ }^{4}$ APHP, Hôpital Universitaire Necker-Enfants Malades, Centre de Référence Déficits Immunitaires Héréditaires (CEREDIH), Paris, France ${ }^{5}$ Univ. Paris Descartes-Sorbonne Paris Cité, Institut Imagine, Paris, France ${ }^{6}$ INSERM, Paris, France ${ }^{7}$ APHP, Hôpital Universitaire Necker-Enfants Malades, Unité d'Immunologie-Hématologie et Rhumatologie Pédiatrique, Paris, France ${ }^{8}$ Institut Pasteur, Unité de Lymphopoièse, INSERM, Paris, France ${ }^{9}$ Univ. Paris Diderot, Sorbonne Paris Cité, Cellule Pasteur, Paris, France ${ }^{10} \mathrm{MI}-\mathrm{mAbs}$ consortium, Aix-Marseille University, Marseille, France ${ }^{11}$ APHP, Hôpital Necker-Enfants Malades, Biotherapy Unit, Paris, France ${ }^{12}$ APHP, Hôpital Necker-Enfants Malades, Service d'anatomopathologie, Paris, France ${ }^{13} \mathrm{BD}$ Biosciences, Le Pont-de-Claix, France ${ }^{14}$ InnatePharma, Marseille, France ${ }^{15}$ Academic Medical Center at the University of Amsterdam, AZ Amsterdam, the Netherlands ${ }^{16}$ Department of Internal Medicine, Rheumatology \& Immunology, University of Erlangen-Nuremberg, Erlangen, Germany ${ }^{17}$ APHP, Hôpital Necker-Enfants Malades, Study Center of Immunodeficiencies, Paris, France ${ }^{18}$ College de France, Paris, France
\end{abstract}

\section{Abstract \\ Innate lymphoid cells (ILCs) have potent immune functions in experimental conditions in mice, but their contribution to immunity in natural conditions in humans remains unclear. We investigated the presence of ILCs in a cohort of patients with severe combined immunodeficiency (SCID). All ILC subsets were absent in SCID patients carrying mutations of IL2RG or JAK3. T cell reconstitution was observed in SCID patients upon hematopoietic stem cell transplantation}

\footnotetext{
Users may view, print, copy, and download text and data-mine the content in such documents, for the purposes of academic research, subject always to the full Conditions of use:http://www.nature.com/authors/editorial_policies/license.html\#terms

*Corresponding authors: Eric Vivier and Alain Fischer, vivier@ciml.univ-mrs.fr and alain.fischer@aphp.fr.

\#F.V., V.B., B.V. and B.N. contributed equally to this work.

A.F. and E.V. contributed equally to this work.

Author contributions

V.B., B.V. and B.N designed the research, performed experiments and analyzed the data; C. Piperouglou, J.B., N.Y., F. T., T.P., M.P., J.D., A.R. and R. G. performed the experiments and analyzed the data; N. M., N. Z., C. F., G. M., D.M., S.B., H.S., A.D. and C.

Picard. provided key expertise, reagents or samples. F.V., A.F. and E.V. devised and supervised the study, designed the research, and wrote the manuscript, with the help of the other co-authors.

Competing financial interests

E.V. is the cofounder of and a shareholder in Innate Pharma. The other authors have no conflicting financial interest to declare.
} 
(HSCT), but the patients still exhibited drastic reduction of ILCs in the absence of myeloablation, at the exception of rare cases of ILC1 reconstitution. Remarkably, the observed ILC deficiencies were not associated with any particular susceptibility to disease, with a follow-up extending from 7 to 39 years after HSCT. We thus report here the first cases of selective ILC deficiency in humans, and show that ILCs may be dispensable in natural conditions, if T cells are present and B cell function is preserved.

ILCs include natural killer (NK) cells and three other main subsets, ILC1, ILC2 and ILC3, referred as to helper-like ILCs 1, 2, 3. Since their discovery, ILCs have been shown to contribute to wound healing and defense against infection, and recent studies have revealed critical aspects of their differentiation. However, much of the role of ILCs remains to be elucidated, particularly given the diversity of these cells, which adds to the complexity of their analysis.

Unlike T and B cells, ILCs do not express antigen-specific receptors derived from RAGdependent gene rearrangements. Other than this major difference in their recognition repertoire, the ILC and T-cell subsets display striking similarities, as ILC1, ILC2 and ILC3 are driven by the T-bet, GATA- 3 and ROR $\gamma \mathrm{t}$ transcription factors, and produce the cytokines IFN- $\gamma$, IL-5/IL-13 and IL-17/IL-22, respectively 1, 2, 3. In addition, NK cells are driven by Eomes and T-bet, can be cytolytic and produce IFN- $\gamma$, like $\mathrm{CD}^{+} \mathrm{T}$ cells. This similarity of features led to suggestions that ILCs are the innate counterparts of T cells 1, 2, 3. During the course of evolution, two highly parallel systems have thus emerged, with ILCs mimicking the effector profile of $\mathrm{T}$ cell subsets. However, it remains unclear how these two systems are integrated by the innate and adaptive immune systems in natural conditions in humans.

In mice, all ILCs are generated by an Id2-dependent pathway from a common lymphoid progenitor (CLP), which initially differentiates into a common ILC precursor (CILP). CILPs differentiate into three precursors, giving rise to three different lineages: NK-cell precursors (NKPs), lymphoid tissue-inducer precursors (LTiPs), and common helper innate lymphoid precursors (CHILPs). CHILPs express the PLZF transcription factor and give rise to the ILC1, ILC2, and ILC3 subsets. LTi cells are essential for the development of secondary lymphoid organs, such as lymph nodes and Peyer's patches in mice. By contrast, ILC differentiation in humans is poorly understood 4 . For instance, the human counterparts of CILP and CHILP have yet to be described and much remains to be understood about ILC differentiation. NK cell progenitors with a $\mathrm{Lin}^{-} \mathrm{CD} 34^{+} \mathrm{CD} 38^{+} \mathrm{CD} 123^{-} \mathrm{CD} 45 \mathrm{RA}^{+} \mathrm{CD} 7^{+} \mathrm{CD} 10^{+} \mathrm{CD} 127^{-}$phenotype have been found in bone marrow, cord blood and tonsils 5. These cells differentiate exclusively into NK cells and are unable to generate ILC2, ILC3 and other lineages. ILC3 progenitors have been identified in human tonsils and intestinal lamina propria, but not in bone marrow, thymus or peripheral blood 6. A $\mathrm{Lin}^{-} \mathrm{CD} 34^{+} \mathrm{CD} 45 \mathrm{RA}{ }^{+} \mathrm{CD} 117^{+} \mathrm{IL}-1 \mathrm{R} 1{ }^{+} \mathrm{ROR} \gamma \mathrm{t}^{+}$progenitor population that expressed ID2 gave rise in vitro to all ILCs, including NK cells, but not to other leukocyte lineages. This ROR $\mathrm{rt}^{+}$progenitor was selectively found in tonsils, lymph nodes, and spleen, but not in peripheral blood, bone marrow, umbilical cord blood, or thymus 7 .

Severe combined immunodeficiency (SCID) is a life-threatening condition that affects infants and is characterized by defective $\mathrm{T}$ cell development associated with various 
deficiencies of other cell lineages, such as NK, B and myeloid cells 8, 9. Patients present with profound abnormalities in immunity, leading to severe recurrent and fatal infections. The life-threatening nature of SCID requires treatment by allogeneic hematopoietic stem cell transplantation (HSCT) or gene therapy to resolve the immune deficiency syndrome 9,10 , 11. HSCT most often requires a conditioning regimen in the patients to induce myeloablation, and hence favors engraftment. Some SCID patients carry mutations of the $I L 2 R G$ gene (which encodes the $\gamma c$ cytokine receptor subunit SCIDX1) or autosomalrecessive mutations of $J A K 3$. Both these types of mutation result in a complete block of $\mathrm{T}$ and NK cell development 12. We dissected here the differentiation and function of human ILCs, by analyzing these cells in patients with SCID resulting from IL2RG and JAK3 mutations, before and after treatment by allogeneic HSCT. We found that SCID patients with IL2RG and JAK3 mutations were ILC-deficient and continued to display ILC deficiency after HSCT in the absence of myeloablation. No particular susceptibility to disease was observed in these patients. Together with earlier findings for mice 13,14, these results provide evidence for possible redundancy of the protective immune function of ILCs in the presence of a functional adaptive immune system.

\section{Results}

\section{Circulating ILCs in healthy children and adults}

ILC1, ILC2 and ILC3 are mostly present as sedentary cells in tissues, in which they can be maintained by self-renewal 15 . Nevertheless, cells from these ILC subsets are detectable in human peripheral blood 16, 17, 18. Using a panel of conventional lineage markers (Lin:

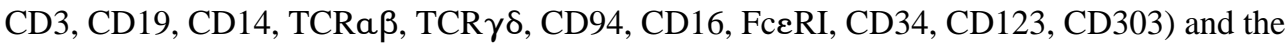
cell surface expression of CD127, CD117 and CRTH2, we identified ILC1 as $\mathrm{Lin}^{-} \mathrm{CD} 127^{+} \mathrm{CD} 117^{-} \mathrm{CRTH} 2^{-}$, ILC2 as $\mathrm{Lin}^{-} \mathrm{CD} 127^{+} \mathrm{CRTH} 2^{+}$and ILC3 as $\mathrm{Lin}^{-} \mathrm{CD} 127^{+} \mathrm{CD} 117^{+} \mathrm{CRTH} 2^{-}$cells among the circulating lymphocytes. NK cells were classically defined as $\mathrm{CD}^{-} \mathrm{CD}^{-} 6^{+}$lymphocytes (Fig. 1a). All ILC subsets were detected in the peripheral blood of healthy children $(6-18$ years) and adults. NK cells were by far the most abundant circulating ILCs (median of $215 \times 10^{3}$ cells $/ \mathrm{ml}$ and $265 \times 10^{3}$ cells $/ \mathrm{ml}$ in healthy children and adults, respectively), and total ILC counts were only $3.8 \times 10^{3}$ cells $/ \mathrm{ml}$ and $1.6 \times 10^{3}$ cells/ml in healthy children and adults, respectively (Fig. 1b,c, Table 1 and Supplementary Table 1). The counts and percentages of helper-like ILCs in peripheral blood lymphocytes decreased with age (Fig. 1b), whereas this trend was not observed for NK cells (Fig. 1c). We also investigated whether there was any association between the counts of circulating ILC1 vs ILC2 vs ILC3 in healthy patients, and whether there was an impact of gender on these values. In accordance with the common origin of helper-like ILCs, there was a strong positive correlation between the absolute numbers of ILC2 and ILC 3 in children and adults, and weak or moderate positive relationship for ILC1 and other ILCs (Supplementary Fig. 1). There was however no difference in gender (data not shown). Consistent with the higher counts of ILCs in children, ILCs were elevated in umbilical cord blood as compared to both children and adult values (Fig. 1d). Circulating ILC1, ILC2 and ILC3 displayed equivalent percentages of total helper-like ILCs and this distribution remained stable across age groups (Fig. 1e). Together, these results establish normal values for human circulating ILCs under natural conditions which are consistent with those 
reported previously for adults 19 , and they pave the way for comparisons with data of circulating ILCs for patients with various pathological conditions.

\section{Absence of circulating ILCs in $\mathrm{T}^{-} \mathrm{B}^{+} \mathrm{NK}^{-}$SCID patients}

ILC1, ILC2 and ILC3 are IL-7-dependent, whereas NK cells are dependent on IL-15 20. The IL-7 and IL-15 signals are integrated via the common $\gamma c$ cytokine receptor subunit and the downstream JAK3 protein tyrosine kinase. NK cell deficiency is a known hallmark of typical cases of SCIDX1 and JAK3 deficiencies 12. We therefore analyzed the presence of other ILCs in SCID patients presenting genetic deficiencies of this pathway. Our cohort comprised 28 SCID patients (12 IL2RG-, $9 J A K 3$ - and $7 R A G$-deficient) and 6 control patients (Supplementary Table 1, Table 2). Among these 28 SCID patients, circulating ILCs could be monitored prior to HSCT in 5 patients and post-HSCT in 20 patients (Supplementary Table 1, Table 2). No circulating ILCs were detected in the peripheral blood of three of the SCID patients (P19, P20 and P21) with JAK3 deficiency prior to HSCT (Fig. 2). These data are consistent with the absence of tonsils and palpable lymph nodes $8,21,22$, suggesting the absence of the LTi subset of ILCs in patients with this condition. In contrast, the ILC compartment was phenotypically normal in patients (C11 and C12) with $R A G 1$-deficiency (Supplementary Fig. 2), consistent with the lack of requirement for $R A G$-dependent DNA recombination events in the development of ILCs in the mouse 2, 3, 23, 24, 25.

\section{ILC deficiency in non-myeloablative HSCT-treated SCID}

We then analyzed the reconstitution of ILCs in $18 \mathrm{~T}^{-} \mathrm{B}^{+} \mathrm{NK}^{-}$SCID patients who had undergone HSCT, 7 to 39 years before the ILC analysis, with mild myeloablation or no myeloablation in all but one (P4) (Table 2, Supplementary Table 1). This cohort consisted of 7 children (P1 to $\mathrm{P} 7$ ) and 11 adults (P8 to $\mathrm{P} 18$ ) with $I L 2 R G$ (12 patients) or $J A K 3$ mutations (6 patients). We also analyzed circulating or tissue-resident ILCs in 6 SCID patients with $R A G 1$ or $R A G 2$ mutations selectively impairing $\mathrm{T}$ and $\mathrm{B}$ cell development, who underwent HSCT after myeloablation (C1, C2, C9, C10, C11, C13). T cell reconstitution was observed in both groups of patients (Fig. 3a,b) 26. In almost all SCID patients of the first group who did not undergo myeloablative HSCT, analysis revealed a highly specific split chimerism, with the $\mathrm{T}$ cells of donor origin, whereas the other leukocyte subsets were of host origin (Table 2) 27. In the SCID patients with $R A G 1$ mutations, long-term analysis revealed complete donor chimerism, providing evidence of donor HSC engraftment (Table 2). ILC2 and ILC3 were barely detectable in the peripheral blood of both pediatric (Fig. 3a) and adult (Fig. 3b) patients with SCID and IL2RG or JAK3 mutations undergoing HSCT. Consistent with previous reports, circulating NK cells were either undetectable or present at only very low numbers in all of these patients (Fig. 3a,b). Similarly, ILC1 were generally undetectable, but low ILC1 counts were obtained for a fraction of children and adults (Fig. 3a,b).

However, high ILC1 counts were obtained for one child who was otherwise healthy (P1) and one adult with chronic lung infections (P12) (Fig. 3a,b). Human ILC1s are highly heterogeneous, and data indicate that ILC1s include cells synthesizing transcripts encoding variable regions of the T-cell antigen receptor 28,29 , and other molecules typically expressed by T cells, such as CD4, CD5, CD6, CD28 and CD27 29, 30. Indeed, most of the ILC1 in HSCT-treated SCID patients and healthy controls were $\mathrm{CD}^{+}$(Supplementary Fig. 3). These results suggest that a substantial fraction of ILC1 may belong to the T-cell lineage 
and that the number of true ILC1 reconstituted in HSCT-treated SCID patients may be even lower than that estimated by classical $\mathrm{Lin}^{-} \mathrm{CD} 127^{+} \mathrm{CD} 117^{-} \mathrm{CRTH} 2^{-}$cell-surface phenotype analysis. Nevertheless, our results show that SCID patients with IL2RG and JAK3 mutations continue to display ILC deficiency after HSCT in the absence of myeloablation.

One obvious limitation of the above analysis was the lack of data on tissue-resident ILCs. Skin and gut paraffin-embedded and frozen tissue sections were obtained from 6 IL2RG or JAK3 SCID patients treated with non-myeloablative HSCT (P1, P3, P5, P11, P14, P16) (Table 2). With the exception of $\mathrm{P} 3$, these biopsies were performed at a distance from the HSCT ( 1 to 10 years). In these samples, the presence of all NKp46 $6^{+}$subsets of ILCs was assessed i.e. NK cells 2, tissue-resident CD127-ILC1 (Ref. 31) and NCR ${ }^{+}$ILC3 (Ref. 2), on the basis of positive staining for NKp46 and an absence of CD3 expression. This analysis was made possible via the generation of a monoclonal antibody screened for its reactivity against paraffin-embedded tissues. In these tissues, NKp $46^{+}$ILCs were not detected or barely detectable as shown in 3 representative $I L 2 R G$ or $J A K 3$ SCID patients treated with non-myeloablative HSCT (Fig. 4a). Frozen sections of gut biopsies from two patients (P1 and P3) were also analyzed. In a representative patient, P3, T cells $\left(\mathrm{CD}^{+}\right)$were detected, but no cell-associated NKp46 staining was detectable, in sharp contrast to the results obtained for controls (Supplementary Fig. 4).

We also sought to also analyze ILC2 in tissue sections corresponding to the samples assessed for NKp46 ${ }^{+}$ILCs. However, the consensus marker of ILC2, CRTH2, cannot be used in tissue sections. An alternative involved reliance on immunofluoresence stainings based on the $\mathrm{CD}^{-}{ }^{-} \mathrm{CD} 11 \mathrm{~b}^{-} \mathrm{ICOS}^{+} \mathrm{ST} 2^{+}$or $\mathrm{Lin}^{-} \mathrm{CD} 34^{-} \mathrm{ST} 2^{+} \mathrm{IL}-17 \mathrm{RB}^{+} \mathrm{KLRG} 1^{+}$phenotype as described earlier 32. However, the density of expression of ST2 varies with ILC2 activation 33 , and thus does not seem as reliable as the CRTH2 staining used to identify circulating ILC2s. We thus used the $\mathrm{CD}^{-} \mathrm{CD}^{-} 1 \mathrm{~b}^{-} \mathrm{ICOS}^{+}$phenotype to evaluate the presence of ILC2s in gut and skin. In these tissues, ILC2s were barely detectable as shown in 2 representative $I L 2 R G$ or $J A K 3$ SCID patients treated with non-myeloablative HSCT (Fig. 4d). Similar conclusions were drawn using the $\mathrm{Lin}^{-} \mathrm{CD} 34^{-} \mathrm{KLRG}^{+}$staining (data not shown).

The specificity of our staining protocols was confirmed by the absence of detectable staining in tissues of two aplastic RAG1 SCID patients (C11 and C13) obtained 3 months after failure of HSCT performed in myeloablative conditions (Supplementary Fig. 5). Thus, SCID patients with $I L 2 R G$ and $J A K 3$ mutations were deficient in circulating and likely tissueresident ILCs, and this deficiency persisted after non-myeloblative HSCT.

\section{ILC reconstitution in myeloablative HSCT}

A question that can be raised from the above results is whether ILC reconstitution may no longer happen in post-natal life in patients with $I L 2 R G$ - or $J A K 3$-deficiency. Only one IL2RG SCID patient investigated in this study underwent myeloablative HSCT (P4) (Table 2). ILC reconstitution was not observed in $\mathrm{P} 4$ peripheral blood (Fig. 3a), indicating that, if myeloablation is one of the factors involved in the reconstitution of circulating ILCs in HSCT-treated SCID patients, it is not the only parameter. However, partial tissue-resident ILC reconstitution was observed in patients treated with HSCT under mild myeloablative conditions, as shown in the representative P15 patient out of the 3 patients examined sharing 
similar HSCT settings (Fig. 4c). We also analyzed the long-term (> 4 years) reconstitution of all subsets of circulating ILCs in patients undergoing myeloablative HSCT for leukemia (ALL, $\mathrm{n}=3$ or AML, $\mathrm{n}=1)$, aplastic anemia $(\mathrm{n}=2)$ or SCID with $R A G 1$ mutations $(\mathrm{n}=2)$. All these patients displayed complete donor chimerism (CDC, Table 2). In these settings, NK cells, ILC1, ILC2 and ILC3 were detected (Fig. 3). The counts of these cells in blood were heterogeneous, particularly for ILC1 (Fig. 3a,b). For ILC2 and ILC3, cell counts in the blood were lower than those of age-matched controls for pediatric patients (Fig. 3a), but were normal (ILC2) or close to normal (ILC3) in adults (Fig. 3b). As expected, complete NK cell reconstitution was observed in pediatric and adult patients (Fig. 3a,b). The longterm reconstitution of circulating ILCs after HSCT was thus observed in these myeloablative conditions. In addition, NKp46 ${ }^{+}$ILCs and ILC2 were readily observed in skin and gut tissues from 2 representative $R A G$-deficient patients (C9 and $\mathrm{C} 10)$ treated with myeloablative HSCT (Fig. 4b,d). Thus, ILCs can be reconstituted postnatally. Therefore, ILC reconstitution can occur in humans after the transplantation of allogeneic hematopoietic grafts, but these cells develop only in myeloablative conditions. Our data also show that the precursors of all ILC subsets are present in human bone marrow and cord blood, the two sources of hematopoietic cells used for HSCT for the SCID patients included in our cohort (Table 2).

\section{ILC reconstitution in mouse HSCT}

To further ascertain the lack of tissue-infiltrating ILCs in HSCT-treated patients, we used mouse models to mimic HSCT in myeloablative and non-myeloablative conditions. CD45.2 $2^{+}$bone marrow LSK $\left(\mathrm{Lin}^{-} \mathrm{Sca} 1^{+} \mathrm{cKit}^{+}\right)$progenitors were sorted as both Flt3 ${ }^{\text {int }}$ multipotent progenitors (MPP) and as Flt $3^{+}$lymphoid-primed multipotent progenitors (LMPP) (Supplementary Fig. 6a), and injected into sub-lethally irradiated or non-irradiated alymphoid CD45.1 $1^{+} \mathrm{Rag}^{-/-} \mathrm{Il2} \mathrm{rg}^{-/}$-mice. Three weeks post-HSCT, ILC populations from liver, lungs and intestine in recipient mice were analyzed. Lung ILC2 $\left(\mathrm{Lin}^{-} \mathrm{Gata}^{+}{ }^{+} \mathrm{CD} 127^{+} \mathrm{ICOS}^{+} \mathrm{ST} 2^{+}\right)$populations were observed in all irradiated mice but undetectable in all non-irradiated mice (Fig. 5, Supplementary Fig. 6b). Similarly, intestinal ILC2 $\left(\mathrm{Lin}^{-} \mathrm{CD} 127^{+} \mathrm{Gata}^{+}{ }^{+} \mathrm{KLRG}^{+}\right)$, and intestinal $\mathrm{NCR}^{+} \mathrm{ILC} 3$ $\left(\mathrm{Lin}^{-} \mathrm{Thy} 1^{+} \mathrm{CD} 127^{+} \mathrm{NKp} 46^{+} \mathrm{ROR} \gamma \mathrm{t}^{+}\right), \mathrm{NCR}^{-} \mathrm{ILC} 3$ (Lin ${ }^{-}$Thy $1^{+} \mathrm{CD} 127^{+} \mathrm{CD} 4^{-} \mathrm{NKp} 46^{-} \mathrm{ROR} \gamma \mathrm{t}^{+}$) and LTi-like ILC3 $\left(\mathrm{Lin}^{-} \mathrm{Thy} 1^{+} \mathrm{CD} 127^{+} \mathrm{CD} 4^{+} \mathrm{NKp} 46^{-} \mathrm{ROR} \gamma \mathrm{t}^{+}\right.$), were reconstituted in the intestinal lamina propria in irradiated $\mathrm{Rag}^{-/-} \mathrm{Il} 2 \mathrm{rg}^{-/-}$recipient mice, but barely detectable in non-irradiated mice (Fig. 5, Supplementary Fig. 6c). Thus, ILC2 and ILC3 reconstitution was effective in all sub-lethally irradiated recipients but not in non-irradiated recipient mice. For ILC1 and NK, the reconstitution was much more effective than for ILC2 and ILC3 in nonmyeloablative conditions, as intestinal lamina propria ILC1 $\left(\mathrm{Lin}^{-} \mathrm{NKp} 46^{+} \mathrm{NK} 1.1^{+} \mathrm{CD} 49 \mathrm{a}^{+} \mathrm{CD} 49 \mathrm{~b}^{-}\right)$and $\mathrm{NK}$ cells $\left(\mathrm{Lin}^{-} \mathrm{NKp} 46^{+} \mathrm{NK} 1.1^{+} \mathrm{CD} 49 \mathrm{a}^{-} \mathrm{CD} 49 \mathrm{~b}^{+}\right)$ of donor origin were equally present in both irradiated and non-irradiated $\mathrm{Rag}^{-/-} \mathrm{II2 \textrm {rg } ^ { - 1 - }}$ recipient mice (Fig. 5, Supplementary Fig. 6c). Although liver ILC1 $\left(\mathrm{Lin}^{-} \mathrm{NKp} 46^{+} \mathrm{NK} 1.1^{+} \mathrm{CD} 49 \mathrm{a}^{+} \mathrm{CD} 49 \mathrm{~b}^{-}\right.$) were detected in irradiated $\mathrm{Rag}^{-/-} \mathrm{II2 \textrm {rg } ^ { - / }}$ recipient mice, they were reduced in non-myeloablative conditions (Fig. 5, Supplementary Fig. 6d). Similarly, lung NK cells $\left(\mathrm{Lin}^{-} \mathrm{NKp} 46^{+} \mathrm{NK} 1.1^{+} \mathrm{CD} 127^{+}\right)$can be reconstituted in nonmyeloablative conditions, but not as efficiently as in irradiated $\mathrm{Rag}^{-1-} \mathrm{II} 2 \mathrm{rg}^{-1-}$ recipient 
mice (Fig. 5, Supplementary Fig. 6b). Nonetheless, circulating NK cells $\left(\mathrm{Lin}^{-} \mathrm{NKp} 46^{+} \mathrm{NK} 1.1^{+} \mathrm{CD} 49 \mathrm{a}^{-} \mathrm{CD} 49 \mathrm{~b}^{+}\right.$) were detected in $\mathrm{Rag}^{-/-} \mathrm{II2} \mathrm{rg}^{-/-}$recipient mice reconstituted in non-myeloablative conditions (data not shown), indicating the sampling of ILCs is correlated to the presence or absence of tissue-resident ILCs. The absence of ILC2 and ILC3 chimerism in non-myeloablative conditions in mice support the data from HSCTtreated SCID patients and suggest the inability of CHILPs in humans and in mice to fully differentiate into appropriate niches as they might compete with endogenous progenitors in these niches. This mechanism of donor HSC engraftment restriction by occupancy of niches by host HSCs is supported by the data showing that the clearance of HSC niches via antibody treatment leads to efficient transplantation 34 .

\section{Human ILC deficiency is not associated with disease}

In HSCT-treated SCID patients, we observed no increase in non-conventional T-cell subsets, such as $\gamma \delta \mathrm{T}$ cells or $\mathrm{Va} 24^{+} \mathrm{V} \beta 11^{+} \mathrm{NKT}$ cells that could compensate for the absence of ILCs on the basis of similarities in effector function (Supplementary Fig. 7a, b). The almost total absence of ILCs in these patients thus provided us with a highly informative situation for evaluating the function of ILCs in natural conditions in humans. Remarkably, this situation of persistent ILC deficiency had no major clinical consequences over very long periods of follow-up ( 7 to 39 years) (Table 3). This cohort of patients was no more prone to infection or inflammation than those undergoing HSCT for other types of SCID with or without myeloablation 26, 35. Growth and quality of life were similar in these groups of patients. A higher than normal incidence of human papillomavirus (HPV) infections, leading to chronic HPV disease, has been observed in HSCT-treated SCID patients with IL2RG or $J A K 3$ mutations 36 . However, no association was detected between HPV infection and the absence of NK cells 36 or other ILCs (this study), consistent with the notion that HPV infections are controlled by IL-2R $\gamma \mathrm{c}$ or JAK-3-dependent signaling in keratinocytes rather than in lymphocytes 37,38 . Nine IL2RG or $J A K 3$ SCID patients from the cohort required immunoglobulin substitution because of residual B cell deficiency due to impaired IL-21R and IL-4R signaling in IL2RG- or JAK3-deficient B cells 39 (Table 3). The pattern of ILC detection in the blood was similar for these patients and for the other patients of the cohort. ILCs thus appear to be dispensable in humans with a functional adaptive immune system, demonstrating redundancy between ILCs and adaptive lymphocytes in humans in natural conditions.

\section{Discussion}

We aimed here to contribute to the understanding of ILC differentiation and function in humans in natural conditions. We focused our analysis on a cohort of $\mathrm{T}^{-} \mathrm{B}^{+} \mathrm{NK}^{-} \mathrm{SCID}$ patients with $J A K 3$ or $I L 2 R G$ deficiencies, and showed that these patients lacked all ILC subsets. These results are consistent with the strict dependence of ILC1, ILC2, ILC3 and NK cells on IL-7 or IL-15 40, 41, 42.

The $J A K 3$ or IL $2 R G$ SCID patients of our cohort underwent allogeneic HSCT, which could be performed in the absence of myeloablation due to the absence of allogeneic immune responses in the recipients. In these HSCT protocols, split chimerism was generally 
observed, with the development of $\mathrm{T}$ cells from the transplanted donor cells, and the other lineages remaining of host origin 27. Progenitor T cells are thought to persist in the long term in the absence of donor HSC engraftment 27, 43. In this setting, no reconstitution of blood NK, ILC2 and ILC3 was observed. In tissues, a marked reduction of NKp46 ${ }^{+}$ILCs and ILC2 was also observed. Thus, SCID patients with IL2RG and JAK3 mutations continued to display ILC deficiency after HSCT in the absence of myeloablation. However, was a trend for a better reconstitution of ILC1 that can even expand in a few patients ( 2 out of 18 in our study). Among all ILC subsets, ILC1 are still ill-defined. In particular, it is possible that some of these ILC1 might correspond to activated T cells with low expression of the CD3-TCR complex. The cell surface expression of CD5, but also CD4, CD28, CD3 molecules and TCR transcript is consistent with this hypothesis $28,29,30$. The lack of a robust consensual definition of ILC1 phenotype is most likely one of the factor leading to the apparent heterogeneity of ILC1.

By contrast, circulating and tissue ILCs were detected in most patients of our cohort who underwent HSCT with myeloablation, consistent with earlier reports showing an early wave of NK cells 44, and slow incomplete ILC reconstitution in these settings 16 . The partial nature of the reconstitution of circulating ILCs in these patients makes it impossible to rule out the possibility of ILC precursors or differentiated ILCs seeding various anatomical sites throughout the body during embryonic development, with subsequent maintenance by selfrenewal in situ, contributing to the production of tissue-infiltrating ILCs after birth 15, 45. In this hypothesis, ILCs could have 2 distinct anatomical and temporal origins: during embryonic life from organs to be identified, and from bone marrow after birth and upon stress conditions, like HSCT. This dual ILC system would parallel the observation of the layered system composed of tissue-resident macrophages originating mainly from yolk sac progenitor cells and of macrophages originating from bone marrow hematopoietic stem cells 46. Nevertheless, our data indicate that ILCs can be reconstituted postnatally. These data are supported by similar results obtained in our mouse model of HSCT.

ILCs are seen as sentinels and local guardians of tissue functions, and many immune functions have been attributed to them, mostly based on experimental challenges in mice or in vitro experiments with human cells 1 . However, the small number of genes selectively expressed by ILCs or ILC subsets 28 and the consequent lack of mouse models selectively targeting ILC subsets has hindered attempts to dissect the selective contribution of these cells to immune defenses in vivo 47 . The drastic reduction of all subsets of circulating and tissue-resident ILCs in transplanted IL2RG and JAK3 SCID patients, at the exception of rare cases of ILC1 reconstitution, provided an informative model to assess the role of ILCs in natural conditions in humans. It is clear from our study that major ILC deficiencies appear to be clinically silent, strongly contrasting with the severe clinical conditions associated with $\mathrm{T}$ and B cell deficiencies. Thus ILCs appear redundant at least in the context of modern medicine and hygiene, providing an alternative view of their immune function. Further very long-term evaluation, beyond 40 years, will nevertheless be required to determine whether $\mathrm{T}$ cell, NK cell and ILC redundancy is maintained in older patients. Our findings are supported by the redundancy between ILC3 and T cells in protection against Citrobacter rodentium intestinal infections in mice 13, 14. They are also consistent with case reports of impaired NK cell effector function without apparent clinical immunodeficiency in humans 48 . 
Noteworthy, NK cells have been shown to contribute to tumor immune-surveillance, and our cohort is too small for addressing this possibility. Given the similarities between ILCs and T cells in terms of transcription factor expression, cytokine secretion and localization, ILCs are probably substituted by $\mathrm{T}$ cells rather than by $\mathrm{B}$ cells. Redundant mechanisms ensuring a robust immune response may have led to the selection of the features common to ILCs and T cells. Our data, indicating that ILCs are part of a multi-layered protective arsenal of immune cells, suggest that it would be useful to dissect the role of ILCs in patients with various genetic or acquired conditions compromising adaptive immunity, including patients on immunosuppressive treatments. The depletion of circulating ILCs has recently been reported in HIV-infected patients not receiving early antiretroviral therapy, but the impact of this lack of ILCs on immunodeficiency and the underlying mechanisms remain unknown 19. Further investigations of the role of ILCs in these conditions, and during embryonic life, early childhood and old age, will be essential to provide a full understanding of ILC biology.

ILCs have also been shown to play a role in reproduction. Indeed, the uterine ILC population, including NK cells, expands during pregnancy, and these cells have been reported to regulate placental development and fetal growth in humans and mice 49. However, two female JAK3-deficient patients included in our study had no signs of fertility disorders, and had healthy babies with a normal birth weight and no other pathological symptoms following clinical event-free pregnancies. ILCs therefore appear to be dispensable for human reproduction in natural conditions.

\section{Methods}

\section{Patients and healthy control individuals}

Patients were treated by allogeneic HSCT in the Immuno-Hematology Department of Necker Children's Hospital (Paris, France) or in the Pediatric Hematology and Oncology Department of Timone Enfants Hospital (Marseille, France). The cells transplanted were obtained from mismatched related donors (MMRD, 19 patients), phenotypically matched related donors (PRD, 5 patients), unrelated umbilical cord blood (UUCB, 4 patients), matched unrelated donors (MUD, 1 patient) or matched sibling donors (MSD, 3 patients). The characteristics of the patient and the HSCT are provided in Table 2 and Supplementary Table 1. Clinical events and the personal variables of the patients were assessed retrospectively, with data collected during annual visits to the outpatient clinic. All clinical events present two years after HSCT or occurring thereafter were recorded, together with the timing, severity, and outcome of these events. Chimerism was determined on total blood or sorted cell lineages, by XY-fluorescence in situ hybridization (FISH) or by the polymerase chain reaction amplification of short tandem repeats. For each cell lineage, mixed chimerism was defined as the presence of $10 \%$ to $90 \%$ donor-derived cells. Blood samples were obtained with consent from patients or families in the context of routine follow-up. In order to minimize variability, exclusion criteria were established. Thus, healthy controls had no infections or current diseases (e.g. hematological, systemic, cardiac, renal). All children were admitted to the Department of Pediatric Surgery of the Timone Hospital (Marseille) during programmed hospitalizations before minor surgery procedure as undescended testes, circumcision or frenulum surgery. These healthy controls were referred to the outpatient 
clinics of Conception Hospital (Marseille) for diagnostic blood testing. They underwent routine blood testing before minor elective surgery. Cord blood were collected from siblings of patients treated for hematological malignancies. When these cord blood units were not compatible with the recipient, parents and guardians have signed an informed consent for studies on these samples before destruction. This study was performed according French rules (Art. L. 1243-1 et Art. L. 1245-2 du Code de la Santé Publique). All patients gave written informed consent for participation, including possible inclusion in genetic studies, and the study was approved by the local ethics committee of the Hôpital Necker (Paris) and the Hôpital de la Timone (Marseille). The characteristics of the patients, including age and sex, are presented in Supplementary Table 1.

\section{Cell preparation and flow cytometry}

Human blood samples were centrifuged on a Ficoll gradient to obtain a preparation enriched in peripheral blood mononuclear cells (PBMCs), which was then frozen, as previously described 50. T and B lymphocytes were quantified with 6-Color BD Multitest and BD Trucount technologies, according to the manufacturer's instructions (Becton Dickinson, San Diego, USA). The monoclonal antibodies (mAbs) used to analyze human cells are provided in Supplementary Table 2. Data were acquired with a FACSCanto II cytometer (T/B/NK subsets) or a Fortessa X20 cytometer (helper-like ILC subsets), both from Becton Dickinson. Data were analyzed with FlowJo software.

\section{Immunofluorescence and immunohistochemistry on tissue sections}

Human intestine and skin biopsy specimens were isolated from HSCT-treated SCID patients with $I L 2 R G$ or $J A K 3$ mutations and control individuals. For immunofluorescence, samples were thoroughly washed in PBS and embedded in optimum cutting temperature compound, frozen in a bath of isopentane cooled on dry ice, and cut into $8 \mu \mathrm{m}$-thick sections. Before staining, sections were fixed by incubation in cold acetone for 10 minutes before saturation. Human NKp46 staining was then performed with a polyclonal goat anti-human NKp46 antibody (R\&D Systems, France), followed by an Alexa488-conjugated donkey anti-goat secondary antibody (Molecular Probes, France). Human CD3 $\varepsilon$ staining was performed with a mouse anti-human Alexa647-conjugated mAb (BD Pharmingen, France). DAPI

(Invitrogen, France) was used to counterstain the nucleus. After staining, the slides were allowed to dry and mounted in Prolong Gold (Invitrogen, France) for examination under a Leica SP5 confocal microscope (Leica). Images were processed with Leica LAS Lite and Adobe Photoshop software. For ILC2 immunohistochemistry, paraffin embedded sections of gut and skin biopsy samples from patients and controls were incubated with rabbit antiKLRG1 (Biorbyt, Cambridge, UK), mouse anti-CD3 (Abcam, Cambridge, UK), rat antiCD11b (R\&D Systems, Minneapolis, USA) and Pacific Blue-labeled anti-lineage markers (Lin; CD3, CD14, CD16, CD19, CD20 and CD56) (Biolegend, London, UK). The following secondary antibodies were used: Dylight-conjugated chicken anti-rat 350 (Agrisera-AB, Vännäs, Sweden), Alexa-Fluor-labeled donkey anti-goat 594, -goat anti-rabbit 660, -donkey anti-mouse 647 (Life Technologies, Darmstadt, Germany) and donkey anti-rabbit 488 (Abcam). Toluidine Blue staining was performed according to standard protocols using a working solution with a $\mathrm{pH}$ between 2.0 and 2.5 . Six randomly chosen high-power fields at 200 -fold magnification per patient or healthy volunteer were evaluated by two experienced 
researchers in a blinded manner. For NKp $46^{+}$ILC immunohistochemistry, paraffin embedded sections of gut and skin biopsy samples from patients and controls were double stained automatically with Leica Bond Max autostainer (Leica Biosystem). Antibody used were polyclonal anti-CD3 (DAKO) and anti-NKp46 (clone 8E5B Innate Pharma, Marseille, France). A full characterization of the $8 \mathrm{E} 5 \mathrm{~B} \mathrm{mAb}$ will be published elsewhere.

\section{Reconstitution experiments in mice}

All mice were C57/BL6/J females used between 6 and 9 week old. $\mathrm{Rag}^{2^{-/-}} \mathrm{II2 \textrm {rg } ^ { - 1 - }}$ mice bearing the CD45.1 allele were used as recipients in the reconstitution experiments.

$\mathrm{CD} 45.2^{+}$hematopoietic progenitors from the bone marrow of C57BL/6 congenic mice were sorted and injected intravenously in the retro-orbital sinus of sub-lethally irradiated (500 rad, cesium source) or non-irradiated $\mathrm{Rag} 2^{--}-\mathrm{II2} \mathrm{rg}^{-/-}$recipient mice.

CD45.2 ${ }^{+} \mathrm{Lin}^{-} \mathrm{Sca}^{+}{ }^{+} \mathrm{CKit}^{+} \mathrm{Flt} 3^{\mathrm{med}}$ (MPP) and $\mathrm{Lin}^{-} \mathrm{Sca}^{+}{ }^{+} \mathrm{CKit}^{+} \mathrm{Flt} 3^{\text {hi }}$ (LMPP) cells were mixed for the bone marrow grafts transplanted into sub-lethally irradiated and non-irradiated CD45.1 $1^{+}$Rag $^{-1-} I I 2 \mathrm{rg}^{-/-}$host mice. Recipients received $7 \times 10^{3}$ adult hematopoietic progenitors and reconstitution was analyzed three weeks after transplantation. The recipient livers, lungs and intestines (lamina propria and intra-epithelial lymphocytes) were analyzed by flow cytometry for the presence of donor $\left(\mathrm{CD} 45.2^{+}\right)$or recipient $\left(\mathrm{CD} 45.1^{+}\right)$lymphoid cell populations.

\section{Statistical analysis}

Statistical analyses were performed with Prism 5 (GraphPad Software, San Diego, CA).

\section{Supplementary Material}

Refer to Web version on PubMed Central for supplementary material.

\section{Acknowledgments}

The authors thank all patients and their families for participating in the study, C. Bonnafous, N. Anceriz (InnatePharma) for the anti-NKp46 mAbs, F. Suarez (Paris), N. Schleinitz (Marseille) and Y. Bertrand (Lyon) for enrolling patients in the study, and the Laboratory of Hematology (P.E. Morange, Marseille) for sample storage. The E.V. laboratory is supported by the European Research Council (THINK Advanced Grant), the Ligue Nationale contre le Cancer (Equipe Labellisée) and by institutional grants from INSERM, CNRS and Aix-Marseille University to CIML. E.V. is a scholar of the Institut Universitaire de France. The A.F. laboratory is supported by the European Research Council (Pidimmune Advanced Grant), by institutional grants from INSERM, Paris Descartes University, Collège de France and an Investissements d'Avenir IHU grant. The R.G. group is supported by institutional grants from Institut Pasteur, INSERM, Université Paris Diderot and the Agence Nationale de la Recherche (Grant "Myeloten"), the Institut National du Cancer and an USPC grant "Mucocell".

\section{References}

1. Klose CS, Artis D. Innate lymphoid cells as regulators of immunity, inflammation and tissue homeostasis. Nat Immunol. 2016; 17:765-774. [PubMed: 27328006]

2. Spits H, et al. Innate lymphoid cells--a proposal for uniform nomenclature. Nat Rev Immunol. 2013; 13:145-149. [PubMed: 23348417]

3. Eberl G, Colonna M, Di Santo JP, McKenzie AN. Innate lymphoid cells: a new paradigm in immunology. Science. 2015; 348:aaa6566. [PubMed: 25999512]

4. Juelke K, Romagnani C. Differentiation of human innate lymphoid cells (ILCs). Curr Opin Immunol. 2016; 38:75-85. [PubMed: 26707651] 
5. Renoux VM, et al. Identification of a Human Natural Killer Cell Lineage-Restricted Progenitor in Fetal and Adult Tissues. Immunity. 2015; 43:394-407. [PubMed: 26287684]

6. Montaldo E, Juelke K, Romagnani C. Group 3 innate lymphoid cells (ILC3s): Origin, differentiation, and plasticity in humans and mice. Eur J Immunol. 2015; 45:2171-2182. [PubMed: 26031799]

7. Scoville SD, et al. A Progenitor Cell Expressing Transcription Factor RORgammat Generates All Human Innate Lymphoid Cell Subsets. Immunity. 2016; 44:1140-1150. [PubMed: 27178467]

8. Buckley RH. Molecular defects in human severe combined immunodeficiency and approaches to immune reconstitution. Annu Rev Immunol. 2004; 22:625-655. [PubMed: 15032591]

9. Fischer A, Hacein-Bey-Abina S, Cavazzana-Calvo M. Gene therapy for primary adaptive immune deficiencies. J Allergy Clin Immunol. 2011; 127:1356-1359. [PubMed: 21624615]

10. Gennery AR, et al. Transplantation of hematopoietic stem cells and long-term survival for primary immunodeficiencies in Europe: entering a new century, do we do better? J Allergy Clin Immunol. 2010; 126:602-610.e601-611. [PubMed: 20673987]

11. Buckley RH. Transplantation of hematopoietic stem cells in human severe combined immunodeficiency: longterm outcomes. Immunol Res. 2011; 49:25-43. [PubMed: 21116871]

12. Fischer A. Primary immunodeficiency diseases: an experimental model for molecular medicine. Lancet. 2001; 357:1863-1869. [PubMed: 11410213]

13. Rankin LC, et al. Complementarity and redundancy of IL-22-producing innate lymphoid cells. Nat Immunol. 2016; 17:179-186. [PubMed: 26595889]

14. Song C, et al. Unique and redundant functions of NKp46+ ILC3s in models of intestinal inflammation. J Exp Med. 2015; 212:1869-1882. [PubMed: 26458769]

15. Gasteiger G, Fan X, Dikiy S, Lee SY, Rudensky AY. Tissue residency of innate lymphoid cells in lymphoid and nonlymphoid organs. Science. 2015; 350:981-985. [PubMed: 26472762]

16. Munneke JM, et al. Activated innate lymphoid cells are associated with a reduced susceptibility to graft-versus-host disease. Blood. 2014; 124:812-821. [PubMed: 24855210]

17. Hazenberg MD, Spits H. Human innate lymphoid cells. Blood. 2014; 124:700-709. [PubMed: 24778151]

18. Vallentin B, et al. Innate Lymphoid Cells in Cancer. Cancer immunology research. 2015; 3:11091114. [PubMed: 26438443]

19. Kloverpris HN, et al. Innate Lymphoid Cells Are Depleted Irreversibly during Acute HIV-1 Infection in the Absence of Viral Suppression. Immunity. 2016; 44:391-405. [PubMed: 26850658]

20. Huntington ND, Carpentier S, Vivier E, Belz GT. Innate lymphoid cells: parallel checkpoints and coordinate interactions with T cells. Curr Opin Immunol. 2015; 38:86-93. [PubMed: 26736074]

21. Buckley RH, et al. Human severe combined immunodeficiency: genetic, phenotypic, and functional diversity in one hundred eight infants. The Journal of pediatrics. 1997; 130:378-387. [PubMed: 9063412]

22. Stephan JL, et al. Severe combined immunodeficiency: a retrospective single-center study of clinical presentation and outcome in 117 patients. The Journal of pediatrics. 1993; 123:564-572. [PubMed: 8410508]

23. McKenzie AN, Spits H, Eberl G. Innate lymphoid cells in inflammation and immunity. Immunity. 2014; 41:366-374. [PubMed: 25238094]

24. Diefenbach A, Colonna M, Koyasu S. Development, differentiation, and diversity of innate lymphoid cells. Immunity. 2014; 41:354-365. [PubMed: 25238093]

25. Artis D, Spits H. The biology of innate lymphoid cells. Nature. 2015; 517:293-301. [PubMed: 25592534]

26. Neven B, et al. Long-term outcome after hematopoietic stem cell transplantation of a single-center cohort of 90 patients with severe combined immunodeficiency. Blood. 2009; 113:4114-4124. [PubMed: 19168787]

27. Fischer A, et al. Severe combined immunodeficiency. A model disease for molecular immunology and therapy. Immunol Rev. 2005; 203:98-109. [PubMed: 15661024]

28. Robinette ML, et al. Transcriptional programs define molecular characteristics of innate lymphoid cell classes and subsets. Nat Immunol. 2015; 16:306-317. [PubMed: 25621825] 
29. Bjorklund AK, et al. The heterogeneity of human CD127 innate lymphoid cells revealed by singlecell RNA sequencing. Nat Immunol. 2016; 17:451-460. [PubMed: 26878113]

30. Roan F, et al. CD4+ Group 1 Innate Lymphoid Cells (ILC) Form a Functionally Distinct ILC Subset That Is Increased in Systemic Sclerosis. J Immunol. 2016; 196:2051-2062. [PubMed: 26826243]

31. Fuchs A, et al. Intraepithelial type 1 innate lymphoid cells are a unique subset of IL-12- and IL-15responsive IFN-gamma-producing cells. Immunity. 2013; 38:769-781. [PubMed: 23453631]

32. Wohlfahrt T, et al. Type 2 innate lymphoid cell counts are increased in patients with systemic sclerosis and correlate with the extent of fibrosis. Annals of the rheumatic diseases. 2016; 75:623626. [PubMed: 26338035]

33. Koyasu S. Inflammatory ILC2 cells: disguising themselves as progenitors? Nat Immunol. 2015; 16:133-134. [PubMed: 25594455]

34. Czechowicz A, Kraft D, Weissman IL, Bhattacharya D. Efficient transplantation via antibodybased clearance of hematopoietic stem cell niches. Science. 2007; 318:1296-1299. [PubMed: 18033883]

35. Railey MD, Lokhnygina Y, Buckley RH. Long-term clinical outcome of patients with severe combined immunodeficiency who received related donor bone marrow transplants without pretransplant chemotherapy or post-transplant GVHD prophylaxis. The Journal of pediatrics. 2009; 155:834-840.e831. [PubMed: 19818451]

36. Laffort C, et al. Severe cutaneous papillomavirus disease after haemopoietic stem-cell transplantation in patients with severe combined immune deficiency caused by common gammac cytokine receptor subunit or JAK-3 deficiency. Lancet. 2004; 363:2051-2054. [PubMed: 15207958]

37. Goldschmidt MH, et al. Severe papillomavirus infection progressing to metastatic squamous cell carcinoma in bone marrow-transplanted X-linked SCID dogs. J Virol. 2006; 80:6621-6628. [PubMed: 16775349]

38. Nishio H, Matsui K, Tsuji H, Tamura A, Suzuki K. Immunolocalisation of the janus kinases (JAK)--signal transducers and activators of transcription (STAT) pathway in human epidermis. Journal of anatomy. 2001; 198:581-589. [PubMed: 11430697]

39. Recher M, et al. IL-21 is the primary common gamma chain-binding cytokine required for human B-cell differentiation in vivo. Blood. 2011; 118:6824-6835. [PubMed: 22039266]

40. Huntington ND, et al. IL-15 trans-presentation promotes human NK cell development and differentiation in vivo. J Exp Med. 2009; 206:25-34. [PubMed: 19103877]

41. Satoh-Takayama N, et al. IL-7 and IL-15 independently program the differentiation of intestinal CD3-NKp46+ cell subsets from Id2-dependent precursors. J Exp Med. 2010; 207:273-280. [PubMed: 20142427]

42. Kang J, Coles M. IL-7: the global builder of the innate lymphoid network and beyond, one niche at a time. Semin Immunol. 2012; 24:190-197. [PubMed: 22421575]

43. Cavazzana-Calvo M, et al. Long-term T-cell reconstitution after hematopoietic stem-cell transplantation in primary T-cell-immunodeficient patients is associated with myeloid chimerism and possibly the primary disease phenotype. Blood. 2007; 109:4575-4581. [PubMed: 17272510]

44. Ruggeri L, Aversa F, Martelli MF, Velardi A. Allogeneic hematopoietic transplantation and natural killer cell recognition of missing self. Immunol Rev. 2006; 214:202-218. [PubMed: 17100886]

45. Fan X, Rudensky AY. Hallmarks of Tissue-Resident Lymphocytes. Cell. 2016; 164:1198-1211. [PubMed: 26967286]

46. Perdiguero EG, Geissmann F. The development and maintenance of resident macrophages. Nat Immunol. 2016; 17:2-8. [PubMed: 26681456]

47. Bando JK, Colonna M. Innate lymphoid cell function in the context of adaptive immunity. Nat Immunol. 2016; 17:783-789. [PubMed: 27328008]

48. Parry DA, et al. A homozygous STIM1 mutation impairs store-operated calcium entry and natural killer cell effector function without clinical immunodeficiency. J Allergy Clin Immunol. 2016; 137:955-957 e958. [PubMed: 26560041] 
49. Boulenouar S, et al. The Residual Innate Lymphoid Cells in NFIL3-Deficient Mice Support Suboptimal Maternal Adaptations to Pregnancy. Frontiers in immunology. 2016; 7:43. [PubMed: 26925058]

50. Tomasello E, et al. Mapping of NKp46(+) Cells in Healthy Human Lymphoid and Non-Lymphoid Tissues. Frontiers in immunology. 2012; 3:344. [PubMed: 23181063] 
a

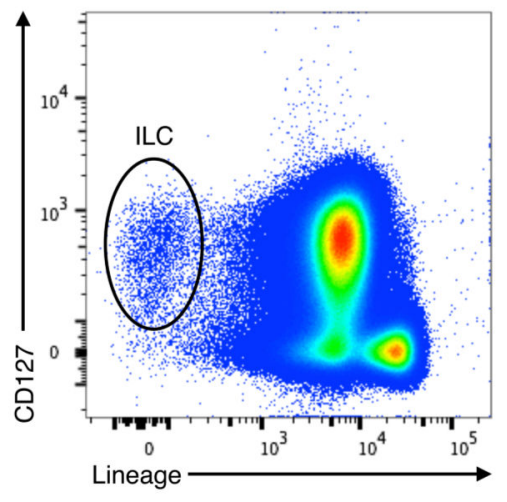

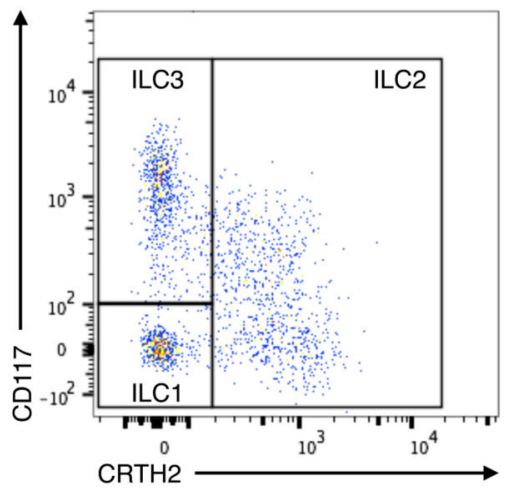

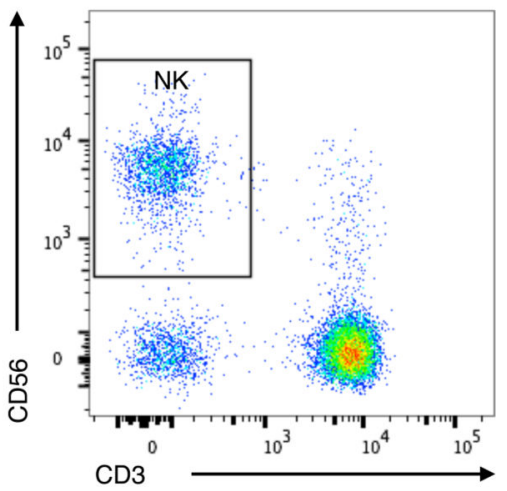

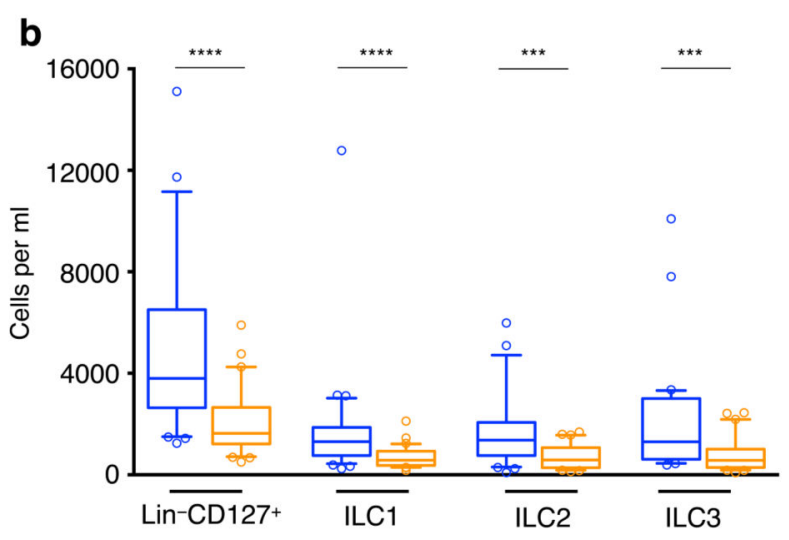

C

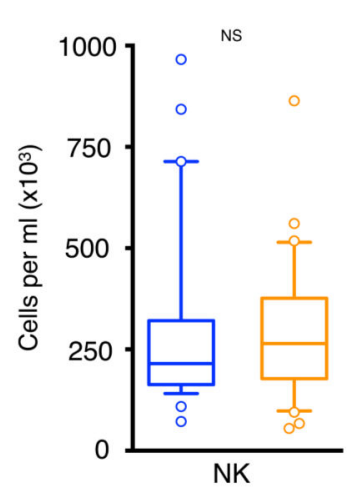

Cord blood

Child PB

Adult PB

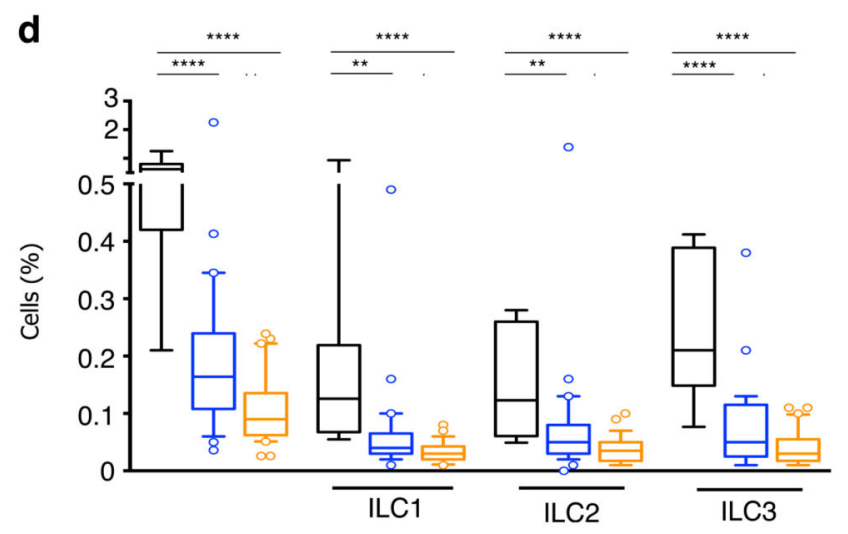

e

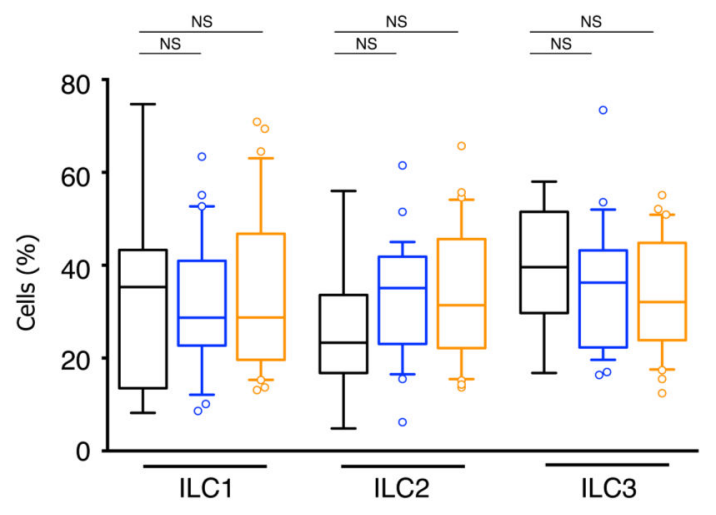

Figure 1. Normal ILC levels in the peripheral blood of healthy pediatric and adult controls (a) Flow cytometric analysis of ILCs in healthy human peripheral blood (PB). ILCs are defined within the $\mathrm{CD} 45^{+}$lymphocyte gate as $\mathrm{Lin}^{-} \mathrm{CD} 127^{+}$cells, with a lineage cocktail containing antibodies directed against CD3, CD19, CD14, TCRa $\beta$, TCR $\gamma \delta$, CD94, CD16, FceRI, CD34, CD123, and CD303. (b) ILC1, ILC2 and ILC3 counts in healthy children (blue, $n=29$ ) and adults (orange, $n=30$ ). Absolute numbers are indicated in numbers of cells per milliliter of peripheral blood. (c) NK cell counts in healthy children (blue, $n=29$ ) and adults (orange, $\mathrm{n}=30$ ). $\mathrm{NK}$ cells are defined as $\mathrm{CD}^{-} \mathrm{CD}^{-} 6^{+}$within the $\mathrm{CD} 45^{+}$ 
lymphocyte gate. Absolute numbers of cells per microliter of peripheral blood are indicated. Distribution of ILC1, ILC2 and ILC3 within lymphocytes (d) or helper-like ILCs (e), is shown for cord blood (black), healthy children (blue) and healthy adults (orange). The subset distribution within the lymphocyte gate is represented in percentages. Medians, $10^{\text {th }}$ and $90^{\text {th }}$ percentiles are shown in box-plots. Outliers are indicated as dots. Data are from one experiment representative of more than 60 independent experiments with similar results (a), 29 and 30 experiments $(\mathbf{b}, \mathbf{c}, \mathbf{d})$ or 7 experiments (e). NS, not significant $(\mathrm{P}>0.05)$. * $\mathrm{P}=0.01$ by Mann-Whitney test. 
a

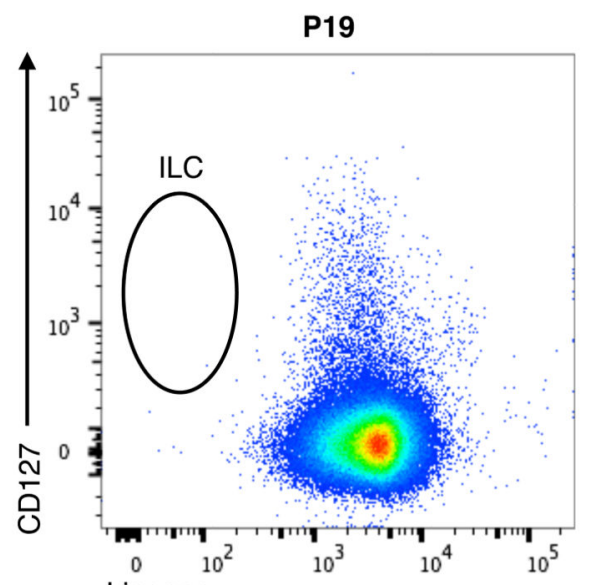

P20

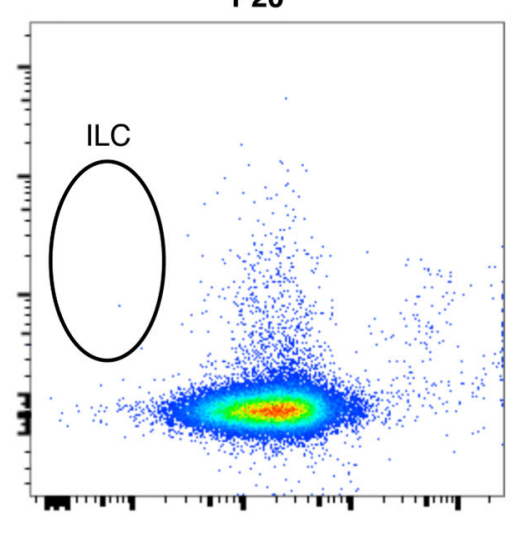

b

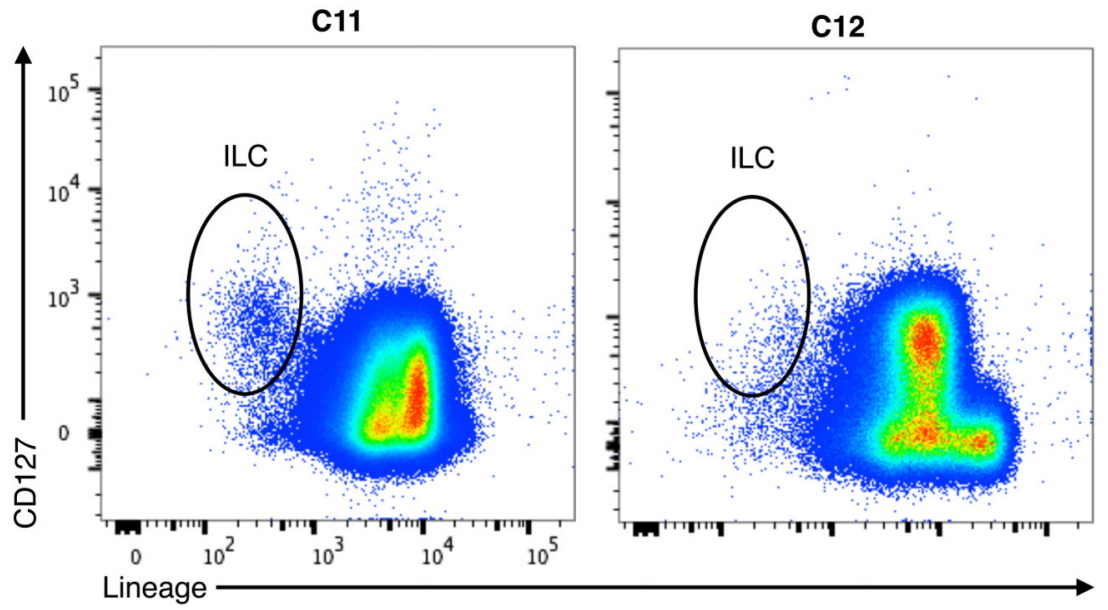

Figure 2. Severe ILC lymphopenia in JAK3 SCID patients

ILCs are defined within the CD $45^{+}$lymphocyte gate as $\mathrm{Lin}^{-} \mathrm{CD} 127^{+}$cells. Comparative ILC staining is shown for (a) 3 representative $J A K 3$ SCID patients (P19, P20, P21) and (b) 2 $R A G 1$ SCID patients $(\mathrm{C} 11, \mathrm{C} 12)$ before HSCT are shown as controls. 

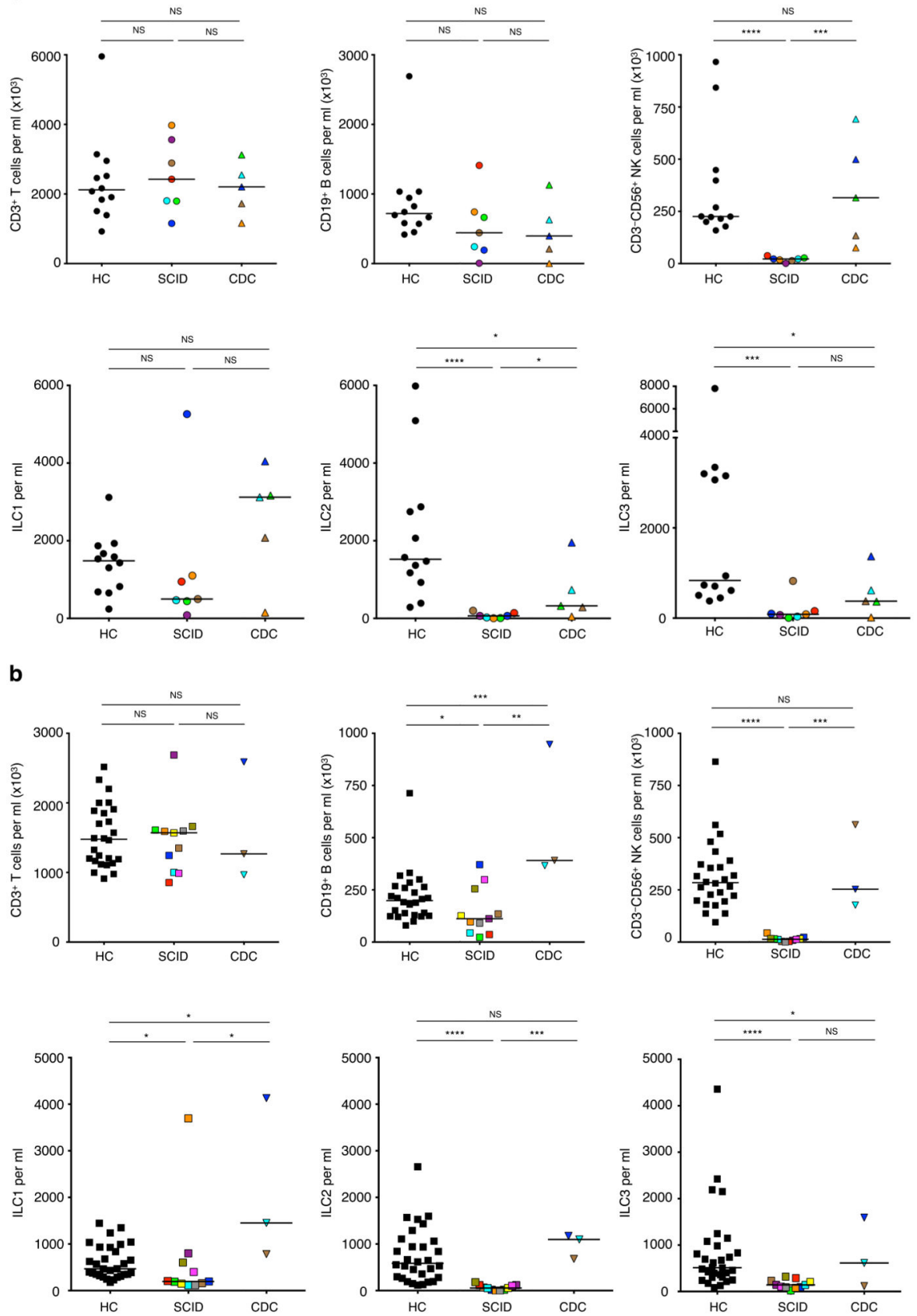

Figure 3. Long-term ILC lymphopenia in HSCT-treated SCID patients

Absolute numbers (cells/ $\mu \mathrm{l})$ are indicated for $\mathrm{CD}^{+} \mathrm{T}$ cells, $\mathrm{CD} 19^{+} \mathrm{B}$ cells and $\mathrm{CD} 3^{-} \mathrm{CD} 56^{+}$ NK cells in the peripheral blood. Absolute numbers (cells/ml) are indicated for ILC subsets in the peripheral blood. (a) Black circles correspond to 6- to 14 year-old healthy controls ( $\mathrm{HC}, \mathrm{n}=12$ ), individual colors represent individual patients and correspond to 6- to 14 yearold $I L 2 R G$ or $J A K 3$ SCID patients $(\mathrm{n}=7)$ and colored triangles correspond to control patients with complete donor chimerism $(\mathrm{CDC}, \mathrm{n}=5)$. (b) Healthy adult controls $(\mathrm{HC}, \mathrm{n}=$ $26)$, adult $I L 2 R G$ or $J A K 3$ SCID patients $(\mathrm{n}=11)$ and control patients with complete donor 
chimerism $(\mathrm{CDC}, \mathrm{n}=3)$ are shown as black squares, colored squares and colored triangles, respectively. NS, not significant $(\mathrm{P}>0.05)$ * $\mathrm{P}=0.05$ by Mann-Whitney test. 


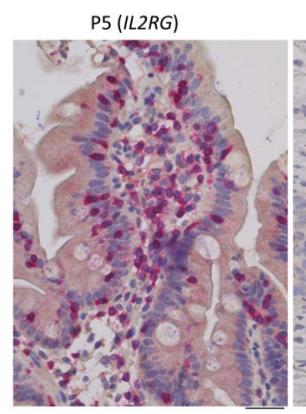

NKp46 CD3

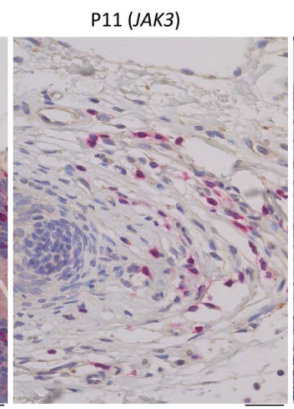

C

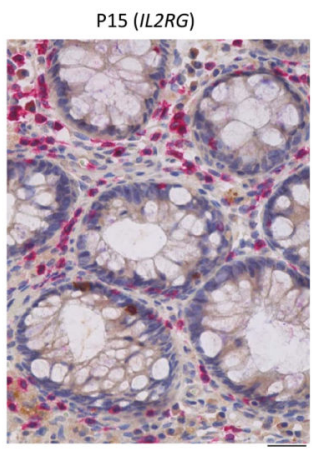

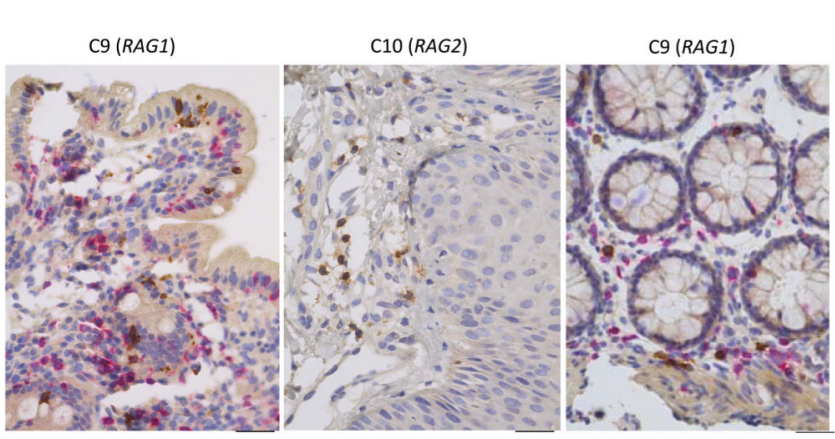

d

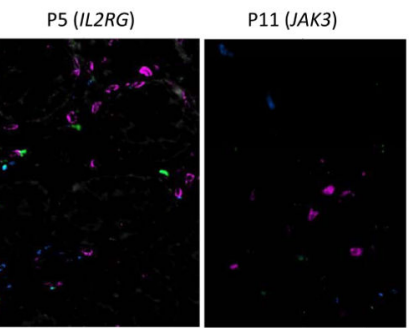

CD3 CD11b ICOS

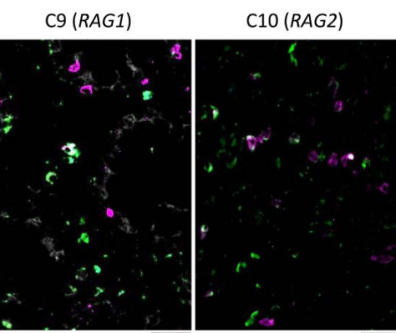

Figure 4. Absence of intestinal and skin ILCs in HSCT-treated SCID patients $\mathrm{CD}^{-}{ }^{-} \mathrm{NK}_{4} 6^{+}$and $\mathrm{CD}^{-}{ }^{-} \mathrm{CD} 11 \mathrm{~b}^{-} \mathrm{ICOS}^{+}$staining was used to identify tissue-resident NKp46 ${ }^{+}$ILCs and ILC2 respectively in indicated organs. (a) left, duodenum sample from P5 (IL2RG) 10 years post non-myeloablative HSCT; middle, skin sample from P11 (JAK3) 18 years post non-myeloablative HSCT; right, colon from $\mathrm{P} 16$ (IL2RG) 5.5 years post nonmyeloablative HSCT. (b) left, duodenum sample from C9 (RAG1) 15 months postmyeloablative HSCT; middle, skin sample from $\mathrm{C} 10$ (RAG2), 4 months post-myeloablative HSCT; right, colon sample from C9. (c) duodenum sample from P15 (IL2RG) 15 months post-myeloablative HSCT. (d) colon sample from P5, skin sample from P11, colon sample from C9 and skin sample from C10. Scale bar, $50 \mu \mathrm{m}$. 

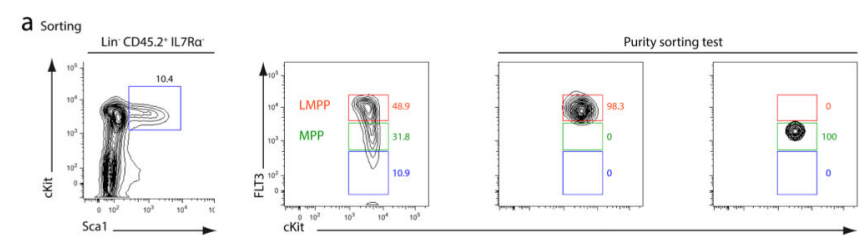

b Lung
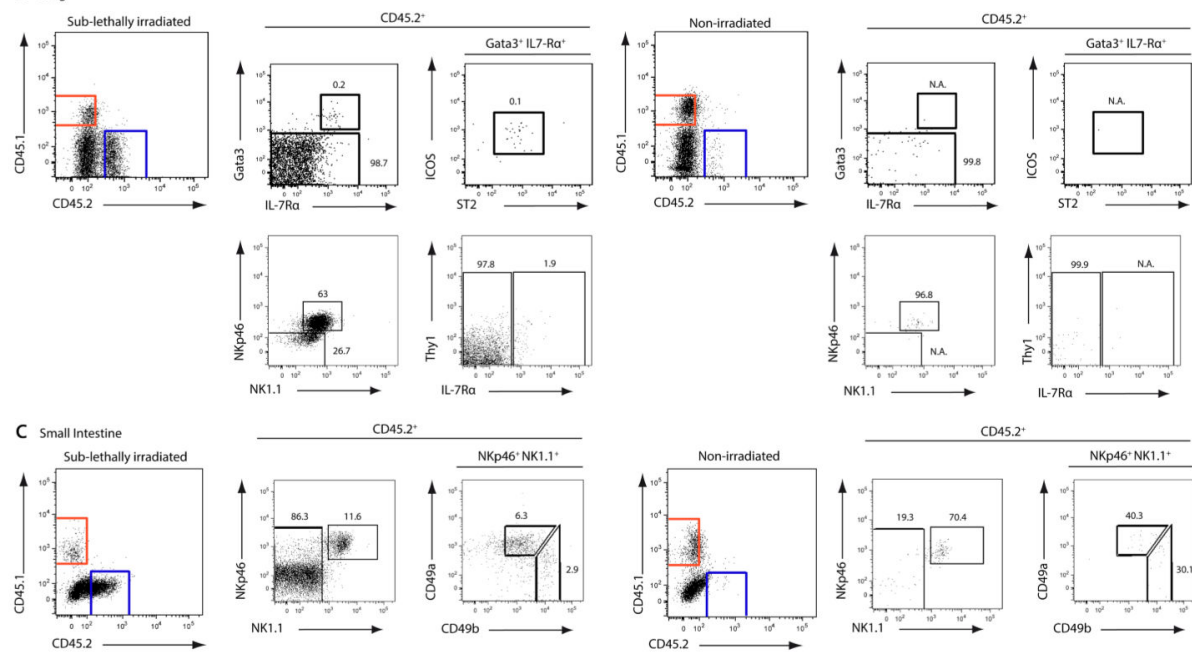

CD45.2+
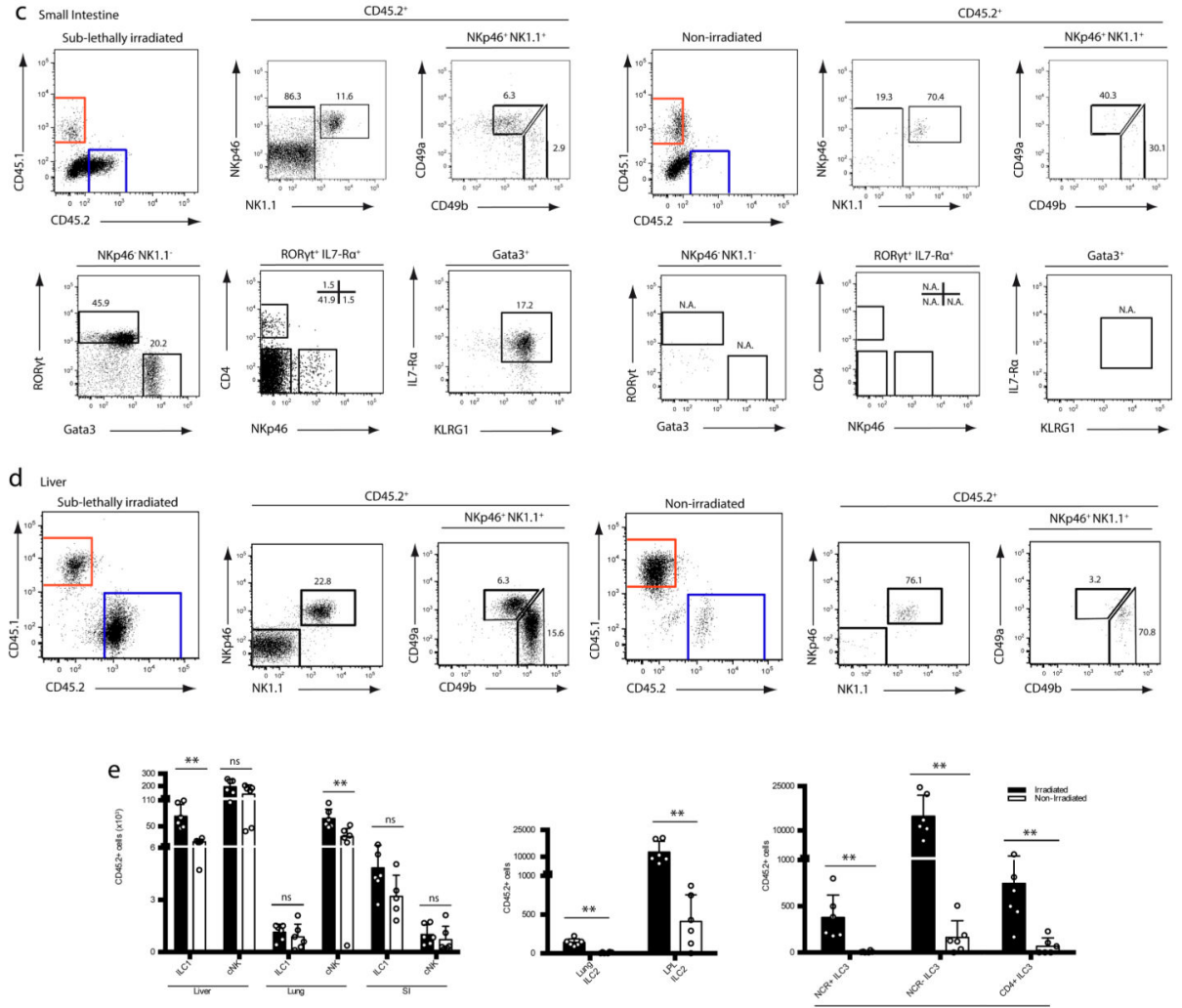

Figure 5. Reconstitution of ILCs after engraftment of adult multipotent progenitors into Rag2 $^{-/-} \mathrm{Il2rg}^{-/-}$deficient mice

Indicated ILC subsets from the lungs, liver and small intestine (SI) were analyzed by flow cytometry after the reconstitution of irradiated and non-irradiated CD $45.1^{+} \mathrm{Rag}^{-/-} \mathrm{II} 2 \mathrm{rg}^{-/}$ recipient mice with multipotent progenitors sorted from CD45.2+ $\mathrm{C} 57 \mathrm{BL} / 6 / \mathrm{J}$ adult bone marrow. By using CD45.1 and CD45.2 congenic markers, donor-derived (CD45.2 $\left.2^{+}\right)$ hematopoietic populations were separated from their recipient $\left(\mathrm{CD} 45.1^{+}\right)$counterparts. ILC1 and NK cells from the lungs were identified as $\mathrm{NKp} 46^{+} \mathrm{NK} 1.1^{+} \mathrm{IL}_{\mathrm{RRa}}{ }^{+}$and $\mathrm{NKp} 46^{+} \mathrm{NK} 1.1^{+} \mathrm{IL} 7 \mathrm{Ra}^{-}$respectively. ILC2 from the lungs were identified as 
$\mathrm{Lin}^{-} \mathrm{Gata}^{+} \mathrm{IL}_{7 \mathrm{Ra}^{+}}$cells co-expressing ICOS and ST2. The expression of CD49a and CD49b was assessed on liver NKp46 ${ }^{+} \mathrm{NK} 1.1^{+}$populations, to identify ILC1 and NK cells respectively. CD3, CD19, Thy1, CD4, NKp46, NK1.1, CD49a, CD49b, KLRG1, ROR $\gamma$ t, Gata3 and IL7Ra were assessed in SI to identify NK, ILC1, ILC2 and ILC3 populations of the lamina propria. Absolute numbers of indicated ILC populations in indicated organs; each symbol represents an individual mouse. The data shown are representative of two experiments with three mice for each condition. N.D.: None-detected. * $\mathrm{P}=0.02$ by MannWhitney test. 


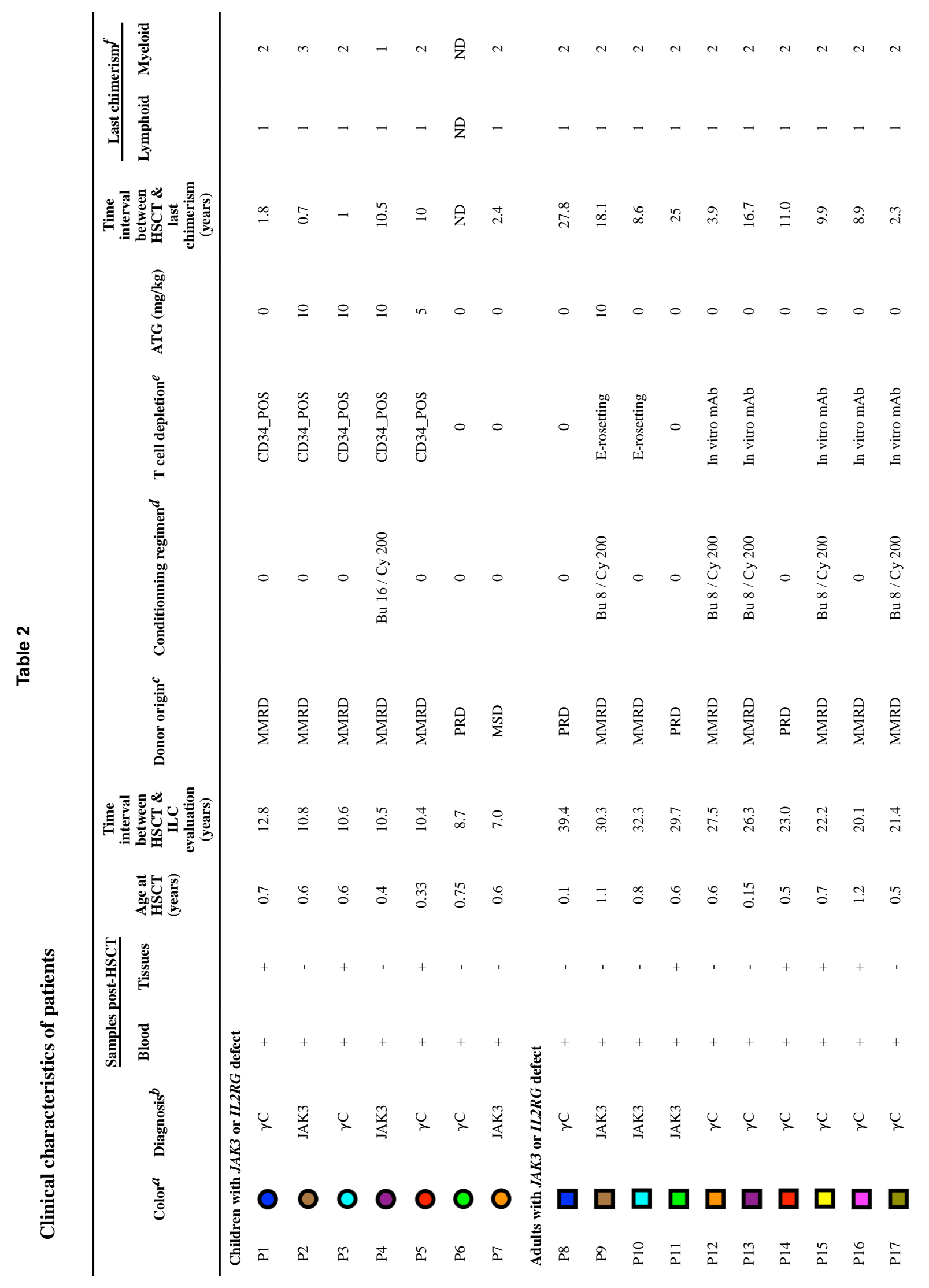

Nat Immunol. Author manuscript; available in PMC 2017 March 12. 


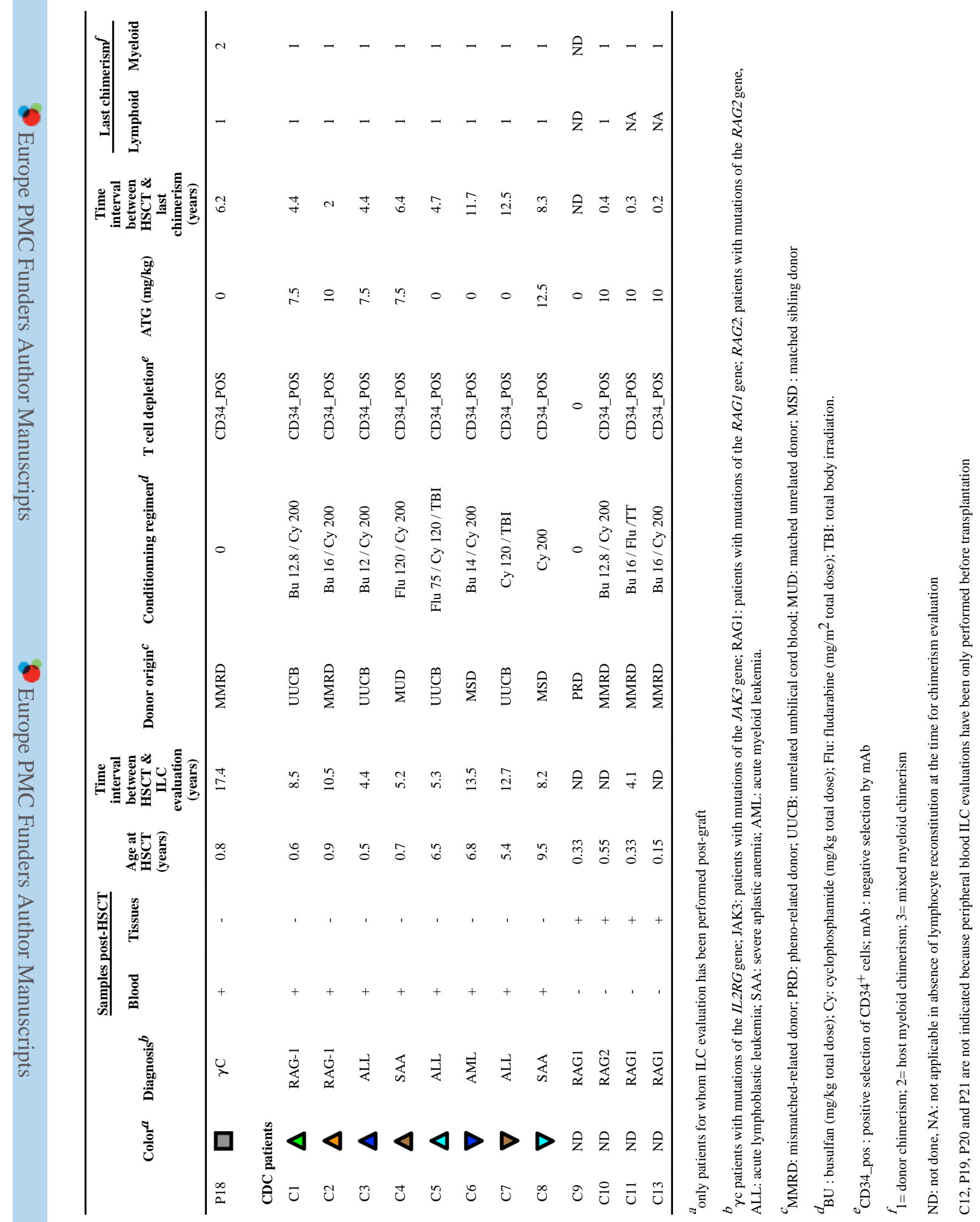

Nat Immunol. Author manuscript; available in PMC 2017 March 12. 


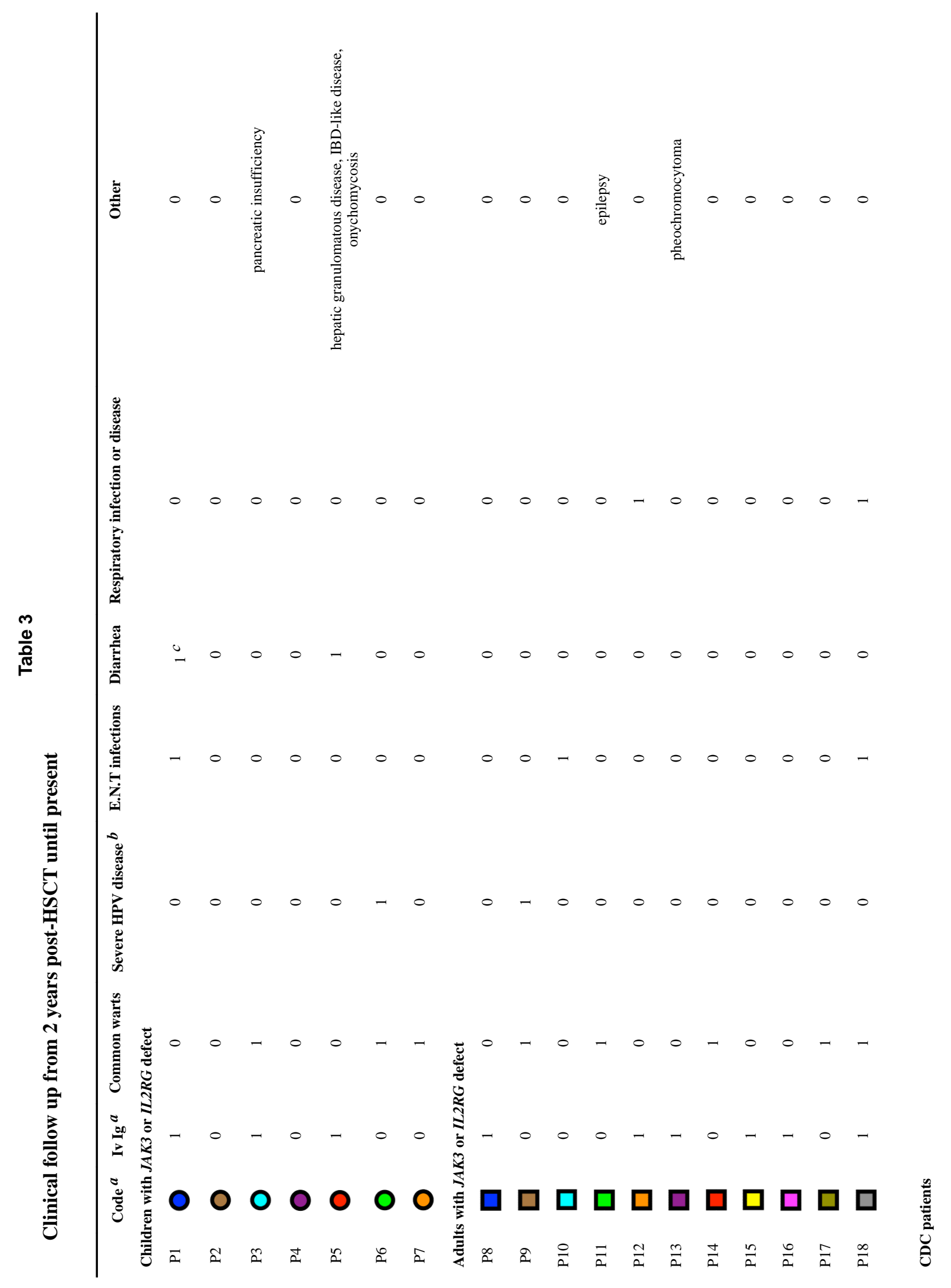

Nat Immunol. Author manuscript; available in PMC 2017 March 12. 


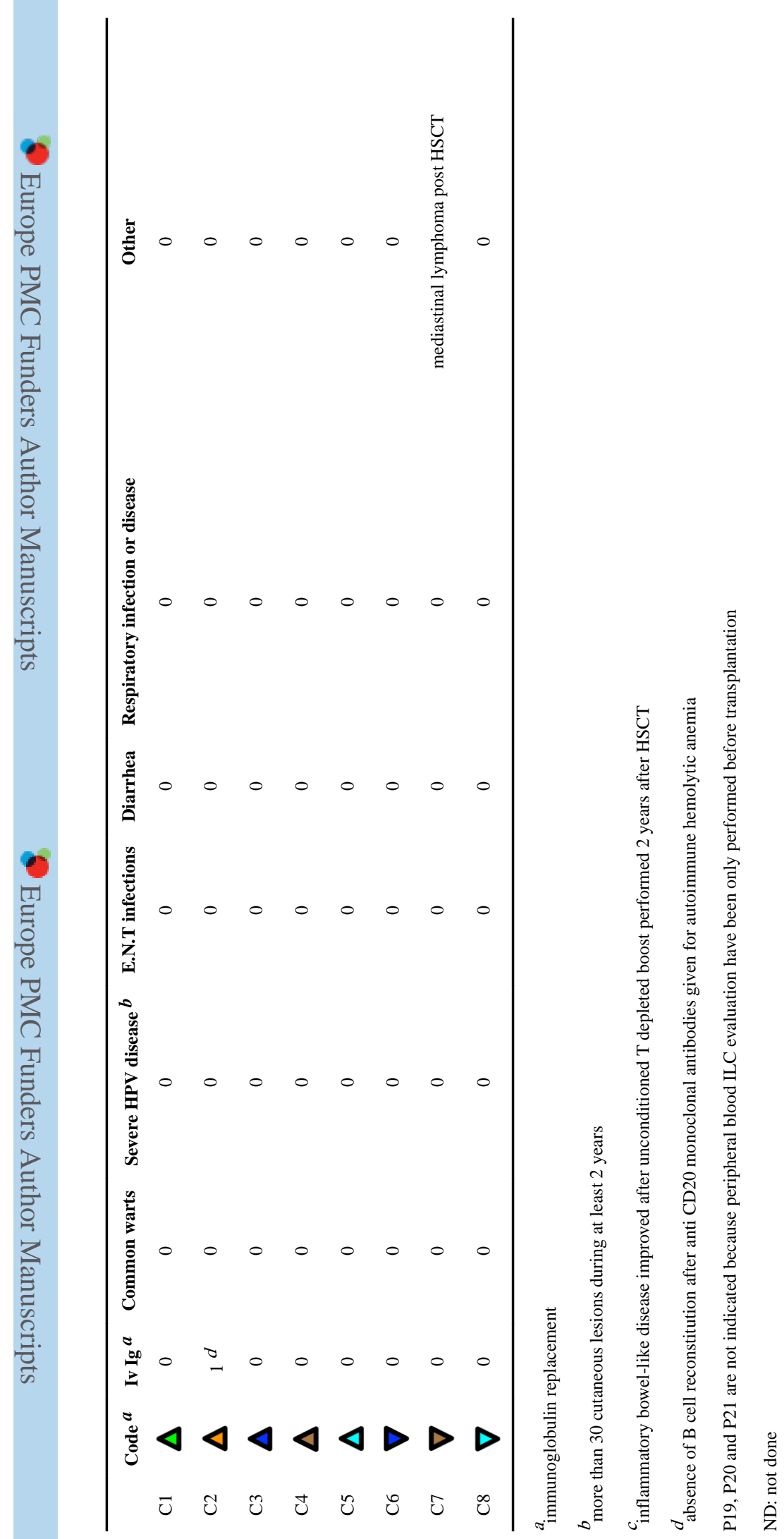

Nat Immunol. Author manuscript; available in PMC 2017 March 12. 